\title{
Fully digital pathology laboratory routine and remote reporting of oral and maxillofacial diagnosis during the COVID-19 pandemic: a validation study
}

\author{
Anna Luíza Damaceno Araújo ${ }^{1}$. Gleyson Kleber do Amaral-Silva ${ }^{1}$ - Maria Eduarda Pérez-de-Oliveira ${ }^{1}$. \\ Karen Patricia Domínguez Gallagher ${ }^{1}$ • Cinthia Veronica Bardalez López de Cáceres ${ }^{1}$ • Ana Luiza Oliveira Corrêa Roza ${ }^{1}$. \\ Amanda Almeida Leite ${ }^{1}$ - Bruno Augusto Linhares Almeida Mariz ${ }^{1}$ - Carla Isabelly Rodrigues-Fernandes ${ }^{1}$. \\ Felipe Paiva Fonseca ${ }^{2}$. Marcio Ajudarte Lopes ${ }^{1}$. Paul M. Speight ${ }^{3}$. Syed Ali Khurram ${ }^{3}$ - Jacks Jorge Júnior ${ }^{1}$. \\ Manoela Domingues Martins ${ }^{4}$ - Oslei Paes de Almeida ${ }^{1}$. Alan Roger Santos-Silva ${ }^{1}$ • Pablo Agustin Vargas ${ }^{1}$
}

Received: 13 January 2021 / Revised: 25 February 2021 / Accepted: 2 March 2021 / Published online: 13 March 2021

(C) The Author(s), under exclusive licence to Springer-Verlag GmbH Germany, part of Springer Nature 2021

\begin{abstract}
The role of digital pathology in remote reporting has seen an increase during the COVID-19 pandemic. Recently, recommendations had been made regarding the urgent need of reorganizing head and neck cancer diagnostic services to provide a safe work environment for the staff. A total of 162 glass slides from 109 patients over a period of 5 weeks were included in this validation and were assessed by all pathologists in both analyses (digital and conventional) to allow intraobserver comparison. The intraobserver agreement between the digital method (DM) and conventional method (CM) was considered almost perfect $(\kappa$ ranged from 0.85 to 0.98 , with $95 \% \mathrm{CI}$, ranging from 0.81 to 1 ). The most significant and frequent disagreements within trainees encompassed epithelial dysplasia grading and differentiation among severe dysplasia (carcinoma in situ) and oral squamous cell carcinoma. The most frequent pitfall from DM was lag in screen mirroring. The lack of details of inflammatory cells and the need for a higher magnification to assess dysplasia were pointed in one case each. The COVID-19 crisis has accelerated and consolidated the use of online meeting tools, which would be a valuable resource even in the post-pandemic scenario. Adaptation in laboratory workflow, the advent of digital pathology and remote reporting can mitigate the impact of similar future disruptions to the oral and maxillofacial pathology laboratory workflow avoiding delays in diagnosis and report, to facilitate timely management of head and neck cancer patients.
\end{abstract}

Keywords Remote reporting · COVID-19 · Digital microscopy · Oral and maxillofacial pathology · Digital pathology · Laboratory workflow

\section{Introduction}

Pablo Agustin Vargas

pavargas@unicamp.br

1 Oral Diagnosis Department, Semiology and Oral Pathology Areas, Piracicaba Dental School, University of Campinas (UNICAMP), Av. Limeira, 901, Bairro Areião, Piracicaba, SP 13414-903, Brazil

2 Department of Oral Surgery and Pathology, School of Dentistry, Federal University of Minas Gerais (UFMG), Belo Horizonte, Minas Gerais, Brazil

3 Unit of Oral \& Maxillofacial Pathology, School of Clinical Dentistry, University of Sheffield, Sheffield, UK

4 Department of Oral Pathology, School of Dentistry, Federal University of Rio Grande do Sul, Porto Alegre, RS, Brazil
The current outbreak of COVID-19 has instigated the need for adaptation of several aspects of modern life with consideration for social distancing, since the aerosolized particles of SARSCov 2 virus can remain airborne for up to 3 hours and through speaking, coughing, and sneezing contaminate surfaces for several hours/days [1]. Mitigation strategies include horizontal isolation, which directly affects the functionality of several primary services, including health care. Dental practices usually require the use of high-speed rotational drills cooled with water, which widely spreads aerosols all over a small office with limited ventilation. Infectious aerosols were considered a key etiologic factor in prior coronavirus outbreaks [2]. In addition, direct or indirect contact with exposed mucosa is related to a 
higher risk for transmission [3]. Previous studies reported a high rate $(91.7 \%)$ of SARS-Cov 2 in the saliva [4] even before lung tissue involvement [5]. Given these circumstances, elective dental procedures are strongly recommended to be postponed.

Recently, recommendations had been made regarding the urgent need of reorganizing services enrolled in the diagnosis of head and neck cancer since the delay histological diagnosis can delay treatment and have an adverse affect on patient prognosis [6]. In this context, incisional/scalpel biopsies remain the standard procedure and should be prioritized as usual despite the risk of SARS-Cov 2 transmission. The need for histological processing of surgical specimens requires pathology laboratories to maintain and monitor their workload, operating with a few staff members (dependent upon availability of safe space). Technology can mitigate this issue with a single additional step of glass slide digitalization which can be easily conducted by one technician. Evidence shows that whole slide images (WSI) are suitable for histopathological diagnosis with a non-inferior performance to light microscopy in several subspecialties of human pathology, including head and neck pathology $[4,7,8]$. Digital pathology can also be a really useful tool for remote discussion of these cases in Multidisciplinary Team Meetings (MDTMs) to plan patient management, in addition to sharing with trainees and consultation with other pathologists.

Despite the strong evidence regarding the diagnostic usefulness of WSI systems in several subspecialties of human pathology, its utilization for primary diagnosis remains limited to only a few services in the UK [9-11], Netherlands [12], and Spain [13]. However, the need for maintaining pathology services despite disruptive challenges such as the COVID-19 pandemic has reinforced the need for digital pathology as an alternative and reliable diagnostic method. Subsequently, a recent survey of experience in the UK [14] shows that several services are already conducting validation studies for the implementation of digital pathology. In addition to digital pathology validation (of histology), the current outbreak has also accelerated remote reporting by pathologists outside their usual work environment, highlighting the need for remote report validation pathology $[15,16]$.

We have previously validated the use of WSI for primary diagnosis in oral and maxillofacial pathology [4]. In this study, we propose validation of remote WSI assessment and reporting for the diagnosis of oral and maxillofacial pathologies to substantiate the creation of the first fully oral digital pathology laboratory in Brazil.

\section{Materials and methods}

\section{Adaptations required in laboratory infrastructure and workflow}

Professionals enrolled in laboratory workflow tasks had their temperature routinely monitored and any occasional symptoms were kept under close surveillance, and staff rotation was adopted to avoid over exposure to the virus, since the correlation among viral load and symptoms/prognosis is still not clear $[17,18]$. Pathology labs are usually designed to constrain fire incidences and are equipped with refrigeration and air-conditioning making them poorly ventilated which can contribute to aerosol suspension. Therefore, some adaptations to the infrastructure and workflow of the pathology laboratory were made, and additional precautions were taken to provide a safe work condition for the staff as seen in Fig. 1: (1) reduction of the number and circulation of staff in the laboratory (one pathologist (1a) and one technician (1b) were enrolled in gross analysis), reduction of the frequency of staff exposure (the team should address a schedule with rotational shifts); (2) exhaust systems - fume hood and exhaust ventswere kept functioning to minimize the potential suspension of microdroplets and a HEPA filter was installed. (3) Disinfection of surfaces, floor, and shoes of the staff prior laboratory use were encouraged; (4) disinfection of plastic containers containing biopsy tissue was reinforced due to the high risk of contamination while the clinician manipulates these recipients within surgery and given the time SARSCov 2 remains viable on this material [19]. (5) After processing the material, masks were also disinfected before being discarded [20]. For appropriate disinfection, a solution with $62-71 \%$ ethanol or $0.1 \%$ sodium hypochlorite within $1 \mathrm{~min}$ ute is indicated $[17,21]$. (6) Stringent and regular handwashing by all staff members was also reinforced. Further steps of processing only required one experienced technician including (7) automated tissue processing; (8) embedding within paraffin blocks; (9) tissue sectioning; (10) staining; and (11) scanning.

The majority of adaptations in the laboratory work flow were related to work security. There were no changes in quality control procedures for gross examination, processing, embedding, microtomy, and staining. To ensure digital image quality control, an additional step of macroscopic evaluation of glass slides previous to scanning was conducted including assessment of clean, well placed and dried coverslips, as well as artifacts/bubble-free slides. After scanning, the digitalized images were checked for out of focus, missing tissue, and striping artifacts. The scanned slides were then uploaded to the institutional server and made available through a link, which redirected the pathologist to a web based WSI viewer enabling online visualization, navigation, and flipping functions.

\section{Study design}

The methodology for this study is based on the guidance for remote reporting of digital pathology slides during periods of exceptional service pressure [22], previously detailed in the RCPath guidance for digital pathology implementation [23]. We undertook the present learning process of validation for 
Fig. 1 Adaptations on pathology laboratory workflow and suggested precautions for the staff members

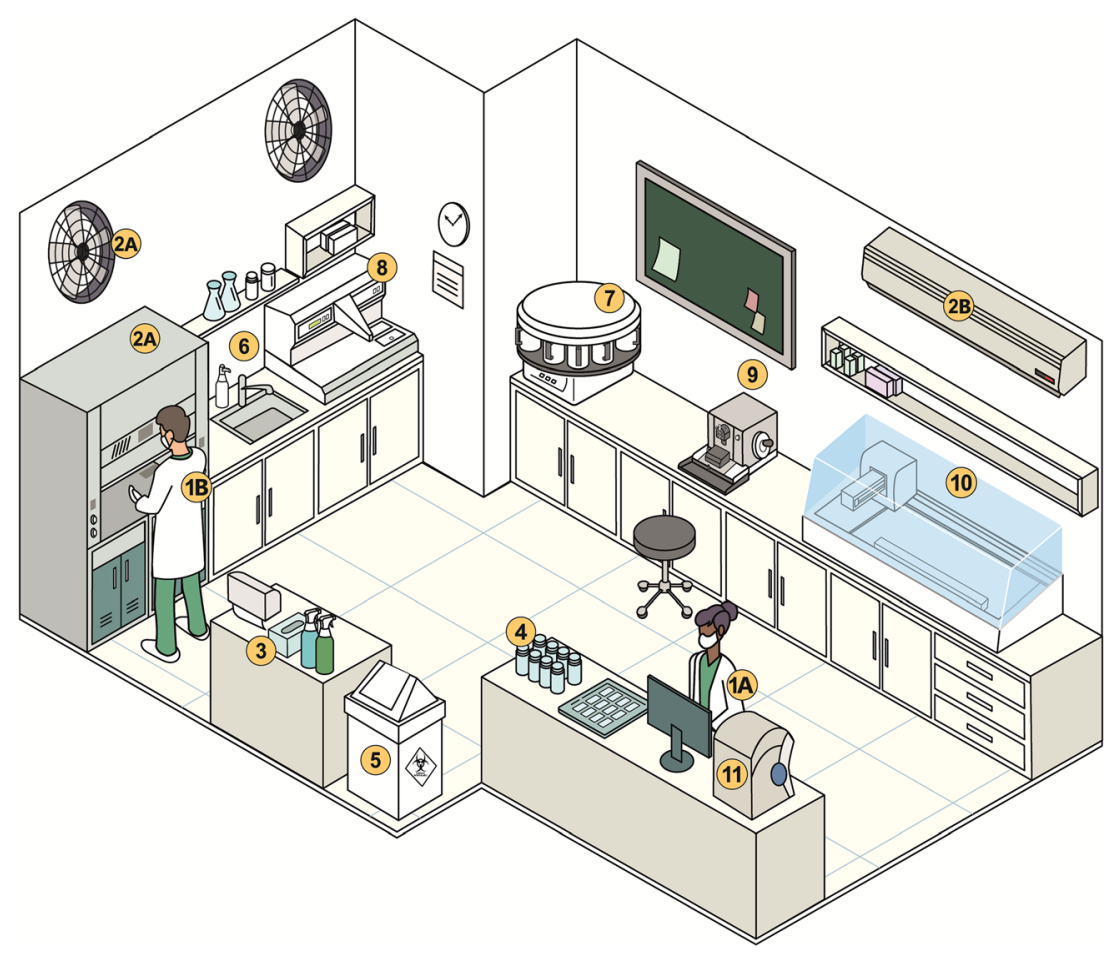

nine months to simultaneously train $8 \mathrm{PhD}$ students for remote reporting of oral and maxillofacial pathologies. This report, however, is based on the learning process of 3 trainees and the lead pathologist, which evaluated the same set of cases during a 5week period experience with a washout period of 1 month [24], as we considered our team sufficiently trained and aligned after almost 9 months of digital pathology diagnostic experience for primary diagnosis purposes. To further consolidate the learning curve and to ensure risk reduction strategies, digital pathology diagnosis and conventional microscope diagnosis were compared when challenging cases or cases with malignant clinical suspicion were assessed. These cases were deferred to glass and reviewed by the lead pathologist using conventional light microscopy (CLM). These risk reduction strategies were associated with expert interconsultation when needed [22].

The sample comprised oral biopsies, consecutively and prospectively selected from the cases processed in the Pathology Laboratory of FOP-UNICAMP for 5 weeks. Only first-time evaluation cases were considered in this analysis. Cases previously assessed and, those which had required further evaluation were only included when the entire set of digital slides (hematoxylin and eosin (H\&E), immunohistochemical and special stains) for each such case were evaluated within the 5 weeks period. A total of 162 glass slides from 109 patients were included in this validation and were assessed by all 4 pathologists in both analyses (digital and conventional) to allow intraobserver comparison.

The glass slides were scanned using the Aperio Digital Pathology System (Leica Biosystems, Wetzlar, Germany) with a spatial sampling of $0.47 \mu \mathrm{m}$ per pixel, with automated focusing and magnification at $\times 20$. WSI included all of the tissue present on conventional glass slides [24]. The workstation specifications are listed in Table 1. Prints of each screen are shown in Fig. 2 to demonstrate visual differences in the pathologist's perception of colors and the brightness of the images. All equipment enrolled in this validation passed the University of Leeds Point of Use QA tool test (http://www. virtualpathology.leeds.ac.uk/research/systems/pouqa/) [22]

Histopathological routine workflow previous to the COVID19 pandemic was conducted in a multi-header CLM 5 position and enhanced by the possibility to share the glass slide visualization via a television set, which receives live video images through a camera attached to the CLM. After the glass slide evaluation, a brief description of histological characteristics is usually provided by the lead pathologist and annotated by one trainee in a temporary sheet and by another trainee in the FOPUNICAMP Anatomopathological Examination Request Website For Biopsies' Records and Histopathological Reports (https://w2.fop.unicamp.br/patologia/index.php?sid=2) in the histological description field. Our online system provides a totally-digital environment, which enables pathologists to see the biopsy request form (as well as clinical photos, serological exams, and radiographs), to consult clinicians about details regarding the patient evolution and disease course, as well as to assess pending cases awaiting for reporting.

The diagnostic method used to validate remote WSI assessment was an online meeting platform (Google Meet). The lead pathologist shared his screen with pathology trainees, allowing a fully digital workflow for case discussion and remote reporting. Digital slides and clinical information 
Table 1 Workstations' specifications (hardware and graphics cards)

\begin{tabular}{lllll}
\hline & Pathologist 1 & Pathologist 2 & Pathologist 3 & Pathologist 4 \\
\hline Model & iMac 21.5 in. & Dell Inspiron 15 (i15-5566) & LENOVO Ideapad s145 & HP Laptop 15-bs0xx \\
Graphics & Intel HD Graphics 5000 & NVIDIA GeForce MX110 2GB & NVIDIA GeForce MX110 2GB & Intel (R) HD Graphics 620 \\
Resolution display & 1920-by-1080 & 1366-by-768 & 1920-by-1080 & 1366-by-768 \\
\hline
\end{tabular}

registered on the website were also shown to all participants for clinicopathological correlation closely resembling the histopathological routine workflow previous to COVID-19 pandemic.

The digital assessment was conducted via an online meeting (Google Meet) for 5 weeks and, after a 1-month washout period, glass slides were analyzed to compare both methods. Diagnoses were classified as (1) concordant; (2) slightly discordant: no clinical or prognostic implications; or (3) discordant. Discordant cases were reviewed by the lead pathologist to reach a preferred diagnosis using both digital and conventional methods, and a stratification of the discordant cases was made as in (1) low degree of difficulty, (2) moderate degree of difficulty, and (3) high degree of difficulty. Additionally, the pathologists were required to list any problems (technical or case related) which may have impaired the digital and/or glass slide evaluation. The timing for each analysis was not assessed as a performance metric because it was necessary to register time individually (for each case) to provide median values as variables and, ask participants to assess their own analysis time would have added bias in this study.

\section{Statistics}

We assessed the global percentage of agreement $\left(P_{\mathrm{o}}\right)$, and $\kappa$ statistics (Fleiss's Kappa) to establish the agreement between $\mathrm{DM}$ and $\mathrm{CM}$ since intraobserver agreement is the primary form of analysis and preferred measurement [24]. $\kappa$ values of $<0.00$ indicates poor agreement, $0.0-0.2$ slight agreement, $0.2-0.4$ fair agreement, $0.4-0.6$ moderate agreement, $0.6-0.8$ substantial or good agreement, and $>0.8$ excellent or almost perfect agreement. The interobserver concordance was not considered in this analysis, since it is more suitable for evaluating a pathologist's performance instead of the method's performance. Statistical analyses were conducted using Real Statistics Resource Pack for Excell.

\section{Results}

The intraobserver metrics were calculated based on fixed categories of the final diagnosis and the interpretation of descriptive diagnosis was based on agreement on certain aspects of the report such as grading dysplasia, microinvasion, and

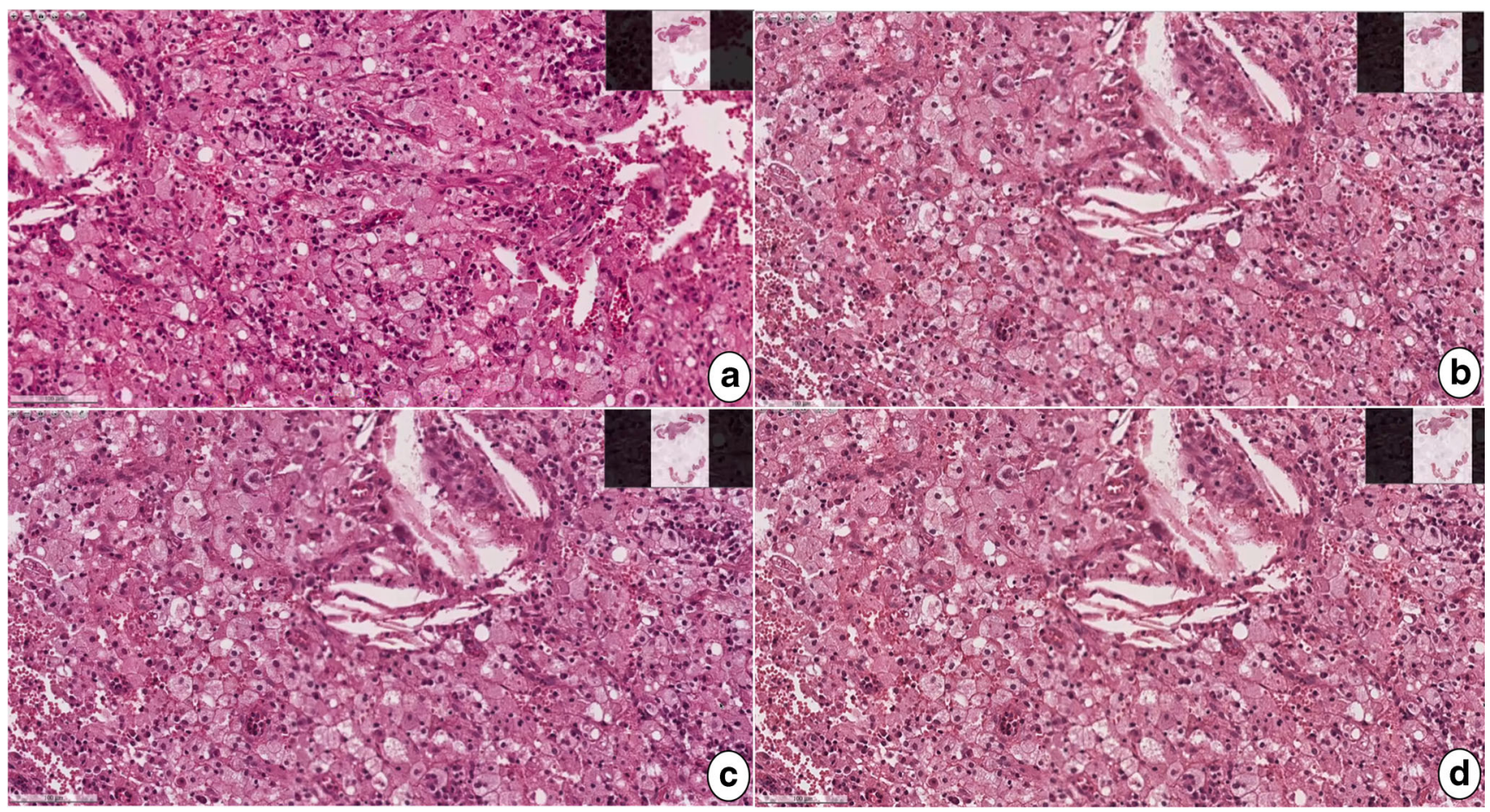

Fig. 2 Prints of each screen enrolled in the present validation. a Lead pathologist; b pathologist 2; $\mathbf{c}$ pathologist 3; $\mathbf{d}$ pathologist 4 
specific structures as perineural invasion, pigmentation of basal layer, vascular structures, and presence of odontogenic components. The intraobserver agreement between DM and $\mathrm{CM}$ was considered almost perfect ( $\kappa$ ranged from 0.85 to 0.98 , with $95 \% \mathrm{CI}$, ranging from 0.81 to 1 ). All intraobserver metrics - the percentage of global agreements for each pathologist, kappa statistics, disagreements, and error rate, as well as pathologist's experiences and reported reasons for diagnostic agreements for each pathologist by method-are shown in Table 2.

Among the lead pathologist's disagreements cases, one was regarding a borderline case of severe dysplasia grade/ OSCC diagnosis (which was deferred to glass and reported as OSCC), and the other encompassed a case of squamous cell carcinoma with a kerathoacantoma-like configuration, which was referred for remote interconsultation to a dermathopathologist. The most frequent pitfall from using this form of DM was lag in screen mirroring, followed by lack of radiographic and clinical photo/information. Despite not being frequent, some reported pitfalls caught included (1) necrosis, pointed as a pitfall for the diagnosis of OSCC for pathologist 2; (2) the need for a higher magnification to assess dysplasia for pathologist 3; (3) inflammation, pointed as a pitfall for the diagnosis of orthokeratinized odontogenic cyst (misinterpreted as dentigerous cyst) for pathologist 4 . Among all 39 discordant diagnoses, the majority of preferred diagnoses were reached out by CM $42(65.6 \%)$, while 30 $(46.8 \%)$ were reached by DM. Individual percentage of preferred diagnosis is shown in Table 2.

The most significant and frequent disagreements within trainees encompassed epithelial dysplasia grading and differentiation between severe dysplasia (carcinoma in situ) and microinvasive OSCC. Among the 12 slides which required dysplasia grading for diagnosis, pathologist 2 had an intraobserver disagreement in $8(66.6 \%)$ slides, pathologist 3 in $6(50 \%)$ slides, and pathologist 4 in $9(75 \%)$ slides. Special attention was required when assessing 7 borderline cases to establish a difference between a severe dysplasia (carcinoma in situ) or a microinvasive OSCC - in 2 slides for pathologist 2 , none for pathologist 3, and in 2 slides for pathologist 4 . Among all discrepant slides, 6 were common to all pathologists Table 3. Other disagreements common to all pathologists were related to the differentiation among (1) paracoccidioidomycosis and coccidioidomycosis fungal particles; (2) periapical granuloma and periapical inflammatory cyst; and (3) odontogenic keratocyst and dentigerous cyst.

\section{Discussion}

The role of digital pathology in remote reporting has increased largely due to the COVID-19 pandemic. Prior to the pandemic, the extent of use of WSI in our institution was limited to teaching [25], pathology conferences, and occasionally consulting experts around the world. Additionally, cases enrolled in MDTM discussion or referred for interconsultations are not usually included in the digital workflow [14]. In our routine practice, interconsultations referred to us are almost always glass slide-based, while our cases referred to external pathologists are digitally shared through a secure link. MDTMs for expert interconsultation have broken down conventional geographic barriers, providing a more definitive diagnosis in a reduced time for challenging cases, and reducing costs associated with transportation of paraffin-embedded blocks/glass slides [16]. In this dataset, interconsultation was needed for one case in which a squamous cell carcinoma presenting in the

Table 2 Intraobserver agreement metrics, pathologists' experience and reported technical/case-related impairments

\begin{tabular}{|c|c|c|c|c|}
\hline & Pathologist 1 & Pathologist 2 & Pathologist 3 & Pathologist 4 \\
\hline Pathologist's experience & Lead Pathologist & Phd student & Phd student & Phd student \\
\hline $\mathrm{P}_{\mathrm{o}}$ & $\begin{array}{l}160 \text { of } 162 \\
(98.76 \%)\end{array}$ & $\begin{array}{l}144 \text { of } 162 \text { slides } \\
(88.8 \%)\end{array}$ & $\begin{array}{l}142 \text { of } 162 \text { slides } \\
(87.65 \%)\end{array}$ & $\begin{array}{l}138 \text { of } 162 \text { slides } \\
(85.1 \%)\end{array}$ \\
\hline Fleiss's Kappa index & $\begin{array}{l}\kappa=0.98 \\
(95 \% \text { CI: } 0.94-1) \\
\text { P-value }=0\end{array}$ & $\begin{array}{l}\kappa=0.88 \\
(95 \% \text { CI: } 0.84-0.92) \\
\text { P-value }=0\end{array}$ & $\begin{array}{l}\kappa=0.86 \\
(95 \% \text { CI: } 0.82-0.90) \\
\text { P-value }=0\end{array}$ & $\begin{array}{l}\kappa=0.85 \\
(95 \% \text { CI: } 0.81-0.89) \\
\text { P-value }=0\end{array}$ \\
\hline Discordancies & $\begin{array}{l}2 \text { of } 162 \text { slides } \\
\text { SL: none } \\
\text { D: }(2 ; 1.2 \%) \\
\text { ER: } 1.2 \%\end{array}$ & $\begin{array}{l}18 \text { of } 162 \text { slides } \\
\text { SL: }(5 ; 27.7 \%) \\
\text { D: }(13 ; 72.2 \%) \\
\text { ER: } 7.4 \%(n=12)\end{array}$ & $\begin{array}{l}20 \text { of } 162 \text { slides } \\
\text { SL: }(8 ; 40 \%) \\
\text { D: }(12 ; 60 \%) \\
\text { ER: } 4.9 \%(n=8)\end{array}$ & $\begin{array}{l}24 \text { of } 162 \text { slides } \\
\text { SL: }(4 ; 16.6 \%) \\
\text { D: }(20 ; 83.3 \%) \\
\text { ER: } 8 \%(\mathrm{n}=13)\end{array}$ \\
\hline Preferred Diagnosis & CM: 2 & $\begin{array}{l}\text { DM: } 8 \\
\text { CM: } 10\end{array}$ & $\begin{array}{l}\text { DM: } 12 \\
\text { CM: } 8\end{array}$ & $\begin{array}{l}\text { DM: } 10 \\
\text { CM: } 14\end{array}$ \\
\hline DM reported pitfalls* & $\begin{array}{l}\text { LSM (10) } \\
\text { Lack of details of } \\
\quad \text { inflammatory cells (1) }\end{array}$ & Lag screen mirroring (11) & $\begin{array}{l}\text { Lag screen mirroring }(7) \\
\text { Higher magnification needed } * *(1)\end{array}$ & Lag screen mirroring (2) \\
\hline
\end{tabular}

$P_{o}$ percentage of agreement, $D$ discordant cases, $S L$ slightly discordant cases, $E R$ error rate of DM (*calculated based on the reference standard diagnosis), $D M$ digital method, $C M$ conventional method. **For dysplasia grading 
Table 3 Discordant cases for all trainees, correspondent preferred diagnoses, and technical/case-related pitfalls

\begin{tabular}{|c|c|c|c|c|c|c|c|}
\hline $\begin{array}{l}\text { WSI } \\
\text { ID }\end{array}$ & Pathologist & Method & Diagnosis & CDis & CDiff & Preferred diagnosis & Technical/case-related pitfalls \\
\hline \multirow[t]{6}{*}{4} & \multirow[t]{2}{*}{ Path2 } & $\mathrm{DM}$ & Periapical granuloma & \multirow[t]{6}{*}{ SD } & \multirow[t]{6}{*}{ LDD } & \multirow[t]{6}{*}{ Periapical granuloma } & - \\
\hline & & $\mathrm{CM}$ & Inflammatory odontogenic cyst & & & & - \\
\hline & \multirow[t]{2}{*}{ Path3 } & $\mathrm{DM}$ & Periapical granuloma & & & & - \\
\hline & & $\mathrm{CM}$ & Inflammatory odontogenic cyst & & & & - \\
\hline & \multirow[t]{2}{*}{ Path4 } & $\mathrm{DM}$ & Periapical granuloma & & & & - \\
\hline & & $\mathrm{CM}$ & Inflammatory odontogenic cyst & & & & - \\
\hline \multirow[t]{6}{*}{50} & \multirow[t]{2}{*}{ Path2 } & $\mathrm{DM}$ & Descriptive (no dysplasia) & \multirow[t]{6}{*}{$\mathrm{D}$} & \multirow[t]{6}{*}{ HDD } & \multirow{6}{*}{$\begin{array}{l}\text { Epitelial dysplasia } \\
\text { (moderate) }\end{array}$} & - \\
\hline & & $\mathrm{CM}$ & Epitelial dysplasia (moderate) & & & & - \\
\hline & \multirow[t]{2}{*}{ Path3 } & $\mathrm{DM}$ & Descriptive (no dysplasia) & & & & Lag screen mirroring \\
\hline & & $\mathrm{CM}$ & Epitelial dysplasia (severe) & & & & - \\
\hline & \multirow[t]{2}{*}{ Path4 } & $\mathrm{DM}$ & Descriptive (no dysplasia) & & & & - \\
\hline & & $\mathrm{CM}$ & Epitelial dysplasia (severe) & & & & - \\
\hline \multirow[t]{6}{*}{103} & \multirow[t]{2}{*}{ Path2 } & $\mathrm{DM}$ & Dentigerous cyst & \multirow[t]{6}{*}{$\mathrm{SD}$} & \multirow[t]{6}{*}{ LDD } & \multirow[t]{6}{*}{ Odontogenic keratocyst } & - \\
\hline & & $\mathrm{CM}$ & Odontogenic keratocyst & & & & - \\
\hline & \multirow[t]{2}{*}{ Path3 } & $\mathrm{DM}$ & Odontogenic keratocyst & & & & - \\
\hline & & $\mathrm{CM}$ & Dentigerous cyst & & & & - \\
\hline & \multirow[t]{2}{*}{ Path4 } & $\mathrm{DM}$ & Dentigerous cyst & & & & - \\
\hline & & $\mathrm{CM}$ & Odontogenic keratocyst & & & & - \\
\hline \multirow[t]{6}{*}{130} & \multirow[t]{2}{*}{ Path2 } & $\mathrm{DM}$ & Descriptive (no dysplasia) & \multirow[t]{6}{*}{$\mathrm{D}$} & \multirow[t]{6}{*}{ LDD } & \multirow{6}{*}{$\begin{array}{l}\text { Epitelial dysplasia } \\
\quad \text { (moderate) }\end{array}$} & - \\
\hline & & $\mathrm{CM}$ & Epitelial dysplasia (moderate) & & & & - \\
\hline & \multirow[t]{2}{*}{ Path3 } & $\mathrm{DM}$ & Descriptive (no dysplasia) & & & & - \\
\hline & & $\mathrm{CM}$ & Epitelial dysplasia (moderate) & & & & - \\
\hline & \multirow[t]{2}{*}{ Path4 } & $\mathrm{DM}$ & Descriptive (no dysplasia) & & & & - \\
\hline & & $\mathrm{CM}$ & Epitelial dysplasia (mild) & & & & - \\
\hline \multirow[t]{3}{*}{$\begin{array}{l}157 \text { and } \\
158\end{array}$} & Path2 & $\begin{array}{l}\mathrm{DM} \\
\mathrm{CM}\end{array}$ & $\begin{array}{l}\text { Paracoccidioidomycosis } \\
\text { Coccidioidomycosis }\end{array}$ & SD & MDD & Paracoccidioidomycosis & $\begin{array}{l}\text { Non-representative biopsy/small } \\
\text { amount of tissue }\end{array}$ \\
\hline & Path3 & $\begin{array}{l}\mathrm{DM} \\
\mathrm{CM}\end{array}$ & $\begin{array}{l}\text { Paracoccidioidomycosis } \\
\text { Coccidioidomycosis }\end{array}$ & & & & $\begin{array}{l}\text { Non-representative biopsy/small } \\
\text { amount of tissue }\end{array}$ \\
\hline & Path4 & $\begin{array}{l}\mathrm{DM} \\
\mathrm{CM}\end{array}$ & $\begin{array}{l}\text { Paracoccidioidomycosis } \\
\text { Coccidioidomycosis }\end{array}$ & & & & $\begin{array}{l}\text { Non-representative biopsy/small } \\
\text { amount of tissue }\end{array}$ \\
\hline 161 & Path2 & $\begin{array}{l}\mathrm{DM} \\
\mathrm{CM}\end{array}$ & $\begin{array}{l}\text { Descriptive (no sugestive of } \\
\text { carcinoma) } \\
\text { Squamous cell carcinoma }\end{array}$ & $\mathrm{D}$ & HDD & $\begin{array}{l}\text { Squamous cell } \\
\text { carcinoma }\end{array}$ & Required a deeper sectioning \\
\hline & Path3 & $\mathrm{DM}$ & $\begin{array}{l}\text { Descriptive (no sugestive of } \\
\text { carcinoma) }\end{array}$ & & & & Required special staining \\
\hline & & $\mathrm{CM}$ & Squamous cell carcinoma & & & & \\
\hline & Path4 & $\mathrm{DM}$ & $\begin{array}{l}\text { Descriptive (no sugestive of } \\
\text { carcinoma) }\end{array}$ & & & & Challenging case \\
\hline & & $\mathrm{CM}$ & Squamous cell carcinoma & & & & \\
\hline
\end{tabular}

$D M$ digital method, $C M$ conventional method, CDis categorization of discordancies, CDiff categorization of difficulty, $D$ discordant, $S D$ slightly discordant, $L D D$ low degree of difficulty, $M D D$ moderate degree of difficulty, $H D D$ high degree of difficulty

neck was interpreted as a keratoacanthoma. According to Patel and coworkers [21], a wide variety of hardware specifications have been used worldwide for interconsultations (telepathology), even in suboptimal conditions. In the present validation, display specification was not ideal as stated by Williams (resolution of 3 megapixels or greater, 24 in. or more for a desktop display) but all equipment passed the University of Leeds Point of Use QA tool test (http://www. virtualpathology.leeds.ac.uk/research/systems/pouqa/) [24]. Experts advise that pathologists should be aware of display specifications (including luminance and contrast) and natural light interference in the digital image assessment not only for interconsultations but also for remote diagnosis in exceptional circumstances such as COVID-19. 
Although we have previously conducted a validation study for primary diagnosis of oral pathology cases [4], the daily pathology practice has largely remained CLM-based. This scenario drastically changed when restrictive measures were introduced for staff safety in our institution. According to Browning, the number of pathologists using WSI for remote reporting is higher now than before the outbreak with validation processes due to start soon or almost completed in many institutions in the UK [14]. This highlights the need to maintain quality control standards while these essential health care services are being provided. Numerous reference/consult centers worldwide have already transitioned to or have introduced a fully digital pathology service with the advantages including the possibility of consulting an expert for difficult cases, better ergonomy, larger field of vision, improvement of the workflow, and quantification of prognostic parameters [12, 13]. In addition, the emergence of digital microscopy in a pandemic scenario not only offers a way to maintain essential health care but also contributes to a re-evaluation of the best practice in pathology. Back and neck pain associated with microscope use has been reported by pathologists as one specific issue which can be overcome by digitial pathology [14]. This same burden was also the initial point of a need for innovation on how reports are produced to further improve ergonomy [26].

Some studies have also stated that digitalization, despite being an extra step, allows better quality control, and also streamlines histotechnical processing of special and immunohistochemical stains. Continued education is also another important role of digital pathology when considering this unprecedented scenario $[14,15]$ and it must be based on best practice recommendations [27]. Pathology trainees conventional training and education now have the opportunity to be engaged in international meetings and discussions with experts around the world in their respective specialties and are likely to remain a valuable resource even in a post-pandemic scenario.

In the present validation study, the intraobserver agreement was considered almost perfect with $P_{\mathrm{o}}=98.7 \%$ for the lead pathologist. An excellent performance was also reported by Hanna and coworkers, who undertook a randomized, prospective study in which researchers had remote reporting validated with a high percentage of agreement (100\%) among DM and CLM [15]. The error rate (ER) obtained when comparing DM diagnosis with a reference standard (in this study, the lead pathologist's diagnosis after reviewing intraobserver discordant cases and establishing a preferred diagnose between them) should be $3 \%$, and is acceptable if not higher than $4 \%$ [28]. The error rate of DM diagnosis is $1.2 \%$ for the lead pathologist, $8.6 \%$ for pathologist $2,7.4 \%$ for pathologist 3 , and $8 \%$ for pathologist 4 . Despite the high ER for trainees, the lead pathologist's ER suggests that experience may have a crucial role when evaluating WSI for primary diagnosis.
Therefore, it is important not only to considerer individual aspects of lesions in such discordances (challenging, subjective, or borderline cases) [8] but also to take into account previous digital pathology experience.

The majority of disagreements identified in this validation enrolled borderline cases (differentiation between severe dysplasia (carcinoma in situ) or microinvasive OSCC, differentiation between squamous cell carcinoma and kerathoacanthoma), as well as dysplasia grading, similar to previous reports $[7,29]$. These disagreements are related to the subjectivity of dysplasia analysis and may be explained by the experience of trainees and their previous background, especially if we consider the disagreements for each pathologist only in the dysplasia category (seven, eight, and five slides for pathologist 1,2 , and 3, respectively) and compare it with only one discordant slide for the lead pathologist (considered a challenging case with high degree of difficulty). Experience should be taken into account, as trainees had experience from different previous services and their interpretation may suffer from variations depending on how involved they were in routine diagnosis and their respective training time. The grade of difficulty in the interpretation of such cases is highly variable. One slide of epithelial dysplasia was classified as a high degree of difficulty case since it required new sections to allow a better assessment of dysplasia grade, while the other epithelial dysplasia WSI was considered a case of low degree of difficulty. It is also important to emphasize the importance of carefully analyze all the tissue present in the slide (conventional or digital) since it is expected that deeper sections would reveal different configurations of the epithelium in the same way that it is not unusual to observe different grades of dysplasia in two synchronous half of the same biopsy. Additionally, the presence of inflammation could lead to confusion in the differentiation between reactive epithelial atypia and oral epitelial dysplasia [30] (Fig. 3).

Others disagreements were related to missing epithelium in digital slides (in those cases, an inflammatory odontogenic cyst was interpreted as a periapical granuloma by the DM), which is probably not related to misinterpretation, lack of knowledge or training time/experience, but to the lack of time and, sometimes, lack of patience to locate all fragments from a curettage biopsy on the screen, since this is not a case of high degree of difficulty. Molin and collaborators reported the lack of time as a reason for possible diagnostic discordance in one case of a missed fungus in as esophagus biopsy [26]. In this particular situation (missing epithelium), this slight discordance does not drastically interfere in treatment decisions. On the other hand, the differentiation among borderline cases such as severe epithelial dysplasia (carcinoma in situ) and OSCC (early stage), as well as dysplasia grading, presents a great dilemma, since it influences the treatment choice [31, $32]$ and management of pre-malignant lesions $[32,33]$. 

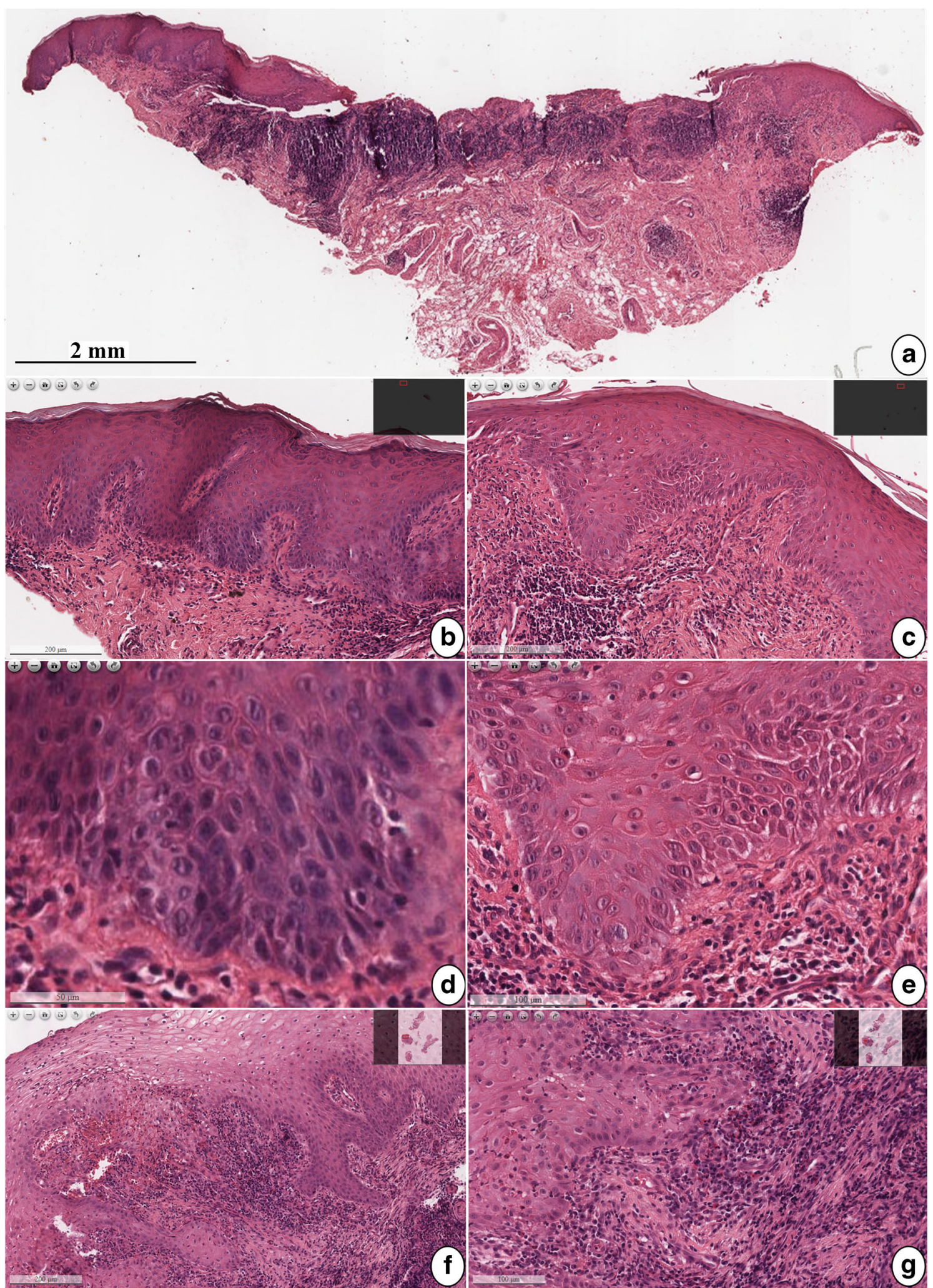

An odontogenic keratocyst was misinterpreted as a dentigerous cyst on DM by pathologists 2 and 4 and on CM by pathologist 3 (as shown in Table 3). Despite trainees not having reported any challenges regarding this specific case, inflammation was identified in the reassessment of the case as a possible pitfall for this disagreement since it can cause 
4 Fig. 3 Discordant case number 50. The biopsy fragment presents extensive ulceration with associated inflammation in the dermis a. The amount of epithelial tissue in both extremities $\mathbf{b}$ and $\mathbf{c}$ presents prominent architectural and cytological changes that require higher power for a better assessment of mitotic figures, nuclear shape, number and arrangement of nucleoli (d and $\mathbf{e}$ ), which can indicate a limitation of the current technology. Additionally, these hyperplastic edges can also present atypical changes that could be hard to differentiate among a reepithelialization event or a true dysplasia [30], which could lead to different interpretations especially if we consider the learning curve of trainees, and the fact that the re-assessment of the cases occurs by CM. Discordant case number 161, the epithelium presents marked acanthosis and epithelial hyperplasia with cell pleomorphism and extensive inflammation in the dermis, which could be associated with more severe dysplasia changes (f and $\mathbf{g}$ ). In this particular microenvironment, inflammation may be underestimated and some lesions interpreted as reactive epithelial atypia instead of oral epithelial dysplasia. The role of inflammation in this scenario is still unclear [30] and played a big role in the trainees' interpretation. Additionally, this case required immunohistochemistry and special stains to rule out infections that could present a configuration of pseudoepitheliomatous hyperplasia, which lead to memorization bias of the correct diagnosis of this particular case, and consequently, a more accurate diagnosis by $\mathrm{CM}$, the ultimate modality of cases re-assessment

epithelial changes. Another case of orthokeratinized odontogenic cyst, discordant only for pathologist 4, was also misinterpreted as a dentigerous cyst due to excessive inflammation that caused several reactive alterations [34, 35]. These cases are not of high complexity once the pathologist has the clinical course and information regarding previous procedures (curettage or marsupialization) that can cause inflammation and epithelium alterations.

Another disagreement common to all pathologists occurred in one case of paracoccidioidomycosis in which trainees diagnosed the fungal particles as coccidioidomycosis. A nonrepresentative biopsy, with only a few larger than expected fungal structures (but still within the range of size compatible with the two hypothesis) without typical sprouts were raised as reasons for disagreement in this slide considered as a case of moderate degree of difficulty. Since both infections are clinically similar and present granulomatous inflammation, morphology of fungal structures and geographic patterns of endemic areas help to achieve the proper diagnosis. Sphere sizes in coccidioidomycosis are larger (10 to $80 \mu \mathrm{m})$ with a double refractile outer wall containing several endospores (no sprouts) while in paracoccidioidomycosis, the sphere size is around 6 to $20 \mu \mathrm{m}$, surrounded by sprouts [36].

In another case, discordant only for pathologist 3 , the need for a higher magnification to assess dysplasia was reported. This technology pitfall has been reported by other groups in different evaluation aspects, for example, when assessing Helicobacter pylori in gastric biopsies or mitosis counting for breast [26]. Dysplasia grading is usually associated with its intrinsic subjectivity of analysis, but not currently associated with the need for higher magnification, since a contextual evaluation takes place based not only on cytological characteristics but also in architectural criteria and evaluation by comparing neighboring cells for pleomorphism. Cross et al. summarized a series of diagnostic difficulties pathologists may experience with assessing dysplasia, detecting metastasis and micrometastasis, identifying mitotic figures, eosinophils, and fine nuclear details highlighted as some of the challenges [22].

All participants in our study reported lag in screen mirroring as the most frequently reported pitfall. Participants in this study did not utilize the institutional virtual private network (VPN). The average home broadband connection in Brazil is around 4.84 Megabits per second (Mbps) and associated with the present resolution displays we achieved a good performance despite recurrent pixelation. The majority of challenges reported in the literature are related to internet speed and workstations limitations but without any impairment to the digital pathology workflow [14]. In one glass slide, the lead pathologist reported the lack of inflammatory cell details by DM [37]. According to Browning, the most reported challenge among students is related to technical difficulties in accessing WSI. Samueli and coworkers reported a survey in which students were trained in 4 modules: self-assigned reading, remote lecture (Zoom), quiz based on digital slide sets, and a frontal review of WSI (Zoom). Eighty percent of students reported technical issues while accessing slides as a challenge but despite that $67 \%$ stated they were more prone to attend online classes [14].

\section{Conclusions}

Given the challenging and unprecedented scenario of the current pandemic, adaptations in the laboratory workflow and digital pathology can aid to mitigate the impact of pandemic COVID-19 outbreak on oral and maxillofacial pathology laboratory routines. This validation study ensures the feasibility of the remote histopathology diagnosis while ensuring social distancing and limiting the spread of SARS-Cov 2.

\section{Overview of results and pathologist perception}

- Flipping is a great advantage of DM (rotation of the image with a single click).

- The wide view provided by a scanned image, automated focus, and easy navigation within different magnifications allows fast recognition of regions of interest, overcoming light, focus, and magnification handling issues, and characteristics of CLM.

- Pathologists should be cautious to not miss important histological structures on DM when their confidence increases. By relying on the wide view provided by DM, pathologists may feel secure to give a diagnosis at a lower magnification, being prone to error - not a technology limitation. 
- Training time (experience) and calibration in pathology are crucial for good performance.

- Reported pitfalls when using a digital environment were as follows:

- Technology-related pitfalls: lag screen mirroring, lack of details of inflammatory cells, and need for a higher magnification to assess dysplasia.

- Case-related pitfalls: bad quality clinical photo, challenging/borderline case, clinical information, and hypothesis do not relate with the histological characteristics, lack of clinical photo/information, lack of radiographs, misleading clinical diagnosis/hypothesis, necrosis, nonrepresentative biopsy/small amount of tissue, need for special staining, the subjectivity of dysplasia analysis;

- Technical processing-related pitfalls: artifact, fixation, the thickness of tissue section, inclusion, staining, and cases that required a deeper tissue sectioning.

\begin{abstract}
Acknowledgements The authors would like to gratefully acknowledge the financial support of the Coordination for the Improvement of Higher Education Personnel (CAPES/PROEX, Brazil), the National Council for Scientific and Technological Development (CNPq, Brazil) and the grants from São Paulo Research Foundation (FAPESP, Brazil) process number: 2009/53839-2, which supported the acquisition of the equipment used. We also would like to acknowledge the dedication of Fabiana Facco Cassarotti for histological processing, Marcondes Sena Filho and Felipe Alexandre Soares for conception and remote support of FOP-UNICAMP Anatomopathological Examination Request Website For Biopsies' Records and Histopathological Reports, and Alexandre Tedesco Favarim for remote support of the institutional server. The authors extend their most sincere gratitude to the illustrator Larissa Ovidio for figure design.
\end{abstract}

Author contribution All authors had substantial contributions to the conception (ALDA, PAV) and draft and design (ALDA, PAV) of this work, as well as participation on the acquisition (GKAS, CVBLC, KPDG, MEPO, ALR, AAL, BALAM, CIRF), analysis (ALDA, PAV), and interpretation (ALDA, PMS, SAK, MAL, JJJ, MDM, OPA, ARSS, PAV) of data for the work.

Funding This study was funded by the Coordination for the Improvement of Higher Education Personnel (CAPES/PROEX, Brazil) process number: 001 , the National Council for Scientific and Technological Development (CNPq, Brazil), and the grants from São Paulo Research Foundation (FAPESP, Brazil) process number: 2009/53839-2, which supported the acquisition of the equipment used.

Data availability If there is a need, all author agree to be accountable for any aspects of the work and we ensure that questions related to the accuracy or integrity of any part of the work are appropriately investigated and resolved. The authors also confirm that the dataset supporting the results reported are available from the corresponding author on reasonable request.

\section{Declarations}

Ethics approval This study was approved by the Piracicaba Dental Ethical Committee (registration number 42236521.2.0000.5418).

Consent to participate Not applicable.
Consent for publication All authors made substantial contributions to the conception or design of the work; or the acquisition, analysis, or interpretation of data; or the creation of new software used in the work The final version of this work was approved for publication by all parts included. The authors state that the material is original, has not been published elsewhere, and is being submitted only to the Virchows Archiv. The final version of this work was reviewed and approved for publication by all parts included. Authors take full responsibility for the work as a whole, including the study design, access to data, and the decision to submit and publish the manuscript.

Competing interests The authors declare no competing interests.

\section{References}

1. The First Affiliated Hospital, Zhejiang University School of Medicine. Handbook of COVID-19 Prevention and Treatment. https://covid-19.alibabacloud.com/. Published 2020

2. Balakrishnan K, Schechtman S, Hogikyan ND, Teoh AYB, McGrath B, Brenner MJ (2020) COVID-19 pandemic: what every otolaryngologist-head and neck surgeon needs to know for safe airway management. Otolaryngol Head Neck Surg 162(6):804 808. https://doi.org/10.1177/0194599820919751

3. Zhang Z, Zhang L, Wang Y (2020) COVID-19 indirect contact transmission through the oral mucosa must not be ignored. J Oral Pathol Med 49:450-451. https://doi.org/10.1111/jop.13019

4. Araújo ALD, Amaral-Silva GK, Fonseca FP, Palmier NR, Lopes MA, Speight PM, de Almeida OP, Vargas PA, Santos-Silva AR (2018) Validation of digital microscopy in the histopathological diagnoses of oral diseases. Virchows Arch 473(3):321-327. https://doi.org/10.1007/s00428-018-2382-5

5. Wang WK, Chen SY, Liu IJ, Chen YC, Chen HL, Yang CF, Chen PJ, Yeh SH, Kao CL, Huang LM, Hsueh PR, Wang JT, Sheng WH, Fang CT, Hung CC, Hsieh SM, Su CP, Chiang WC, Yang JY, Lin JH, Hsieh SC, Hu HP, Chiang YP, Wang JT, Yang PC, Chang SC (2004) SARS Research Group of the National Taiwan University/ National Taiwan University Hospital. Detection of SARS-associated coronavirus in throat wash and saliva in early diagnosis. Emerg Infect Dis 10(7):1213-1219. https://doi.org/10.3201/eid1007.031113

6. Arduino PG, Conrotto D, Broccoletti R (2020) The outbreak of novel coronavirus disease (COVID-19) caused a worrying delay in the diagnosis of oral cancer in north-west Italy: the Turin Metropolitan Area experience. Oral Dis 19. doi: https://doi.org/10.1111/odi.13362.

7. Goacher E, Randell R, Williams B, Treanor D (2017) The diagnostic concordance of whole slide imaging and light microscopy: a systematic review. Arch Pathol Lab Med 141(1):151-161. https:// doi.org/10.5858/arpa.2016-0025-RA

8. Araújo ALD, Arboleda LPA, Palmier NR, Fonsêca JM, de Pauli PM, Gomes-Silva W, Ribeiro ACP, Brandão TB, Simonato LE, Speight PM, Fonseca FP, Lopes MA, de Almeida OP, Vargas PA, Madrid Troconis CC, Santos-Silva AR (2019) The performance of digital microscopy for primary diagnosis in human pathology: a systematic review. Virchows Arch 474(3):269-287. https://doi.org/10.1007/s00428-018-02519-z

9. Williams BJ, Hanby A, Millican-Slater R, Nijhawan A, Verghese E, Treanor D (2018) Digital pathology for the primary diagnosis of breast histopathological specimens: an innovative validation and concordance study on digital pathology validation and training. Histopathology 72(4):662-671. https://doi.org/10.1111/his.13403

10. Williams B, Hanby A, Millican-Slater R, Verghese E, Nijhawan A, Wilson I, Besusparis J, Clark D, Snead D, Rakha E, Treanor D (2020) Digital pathology for primary diagnosis of screen-detected breast lesions - experimental data, validation and experience from 
four centres. Histopathology 76(7):968-975. https://doi.org/10. 1111/his.14079

11. Williams BJ, Ismail A, Chakrabarty A, Treanor D (2020) Clinical digital neuropathology: experience and observations from a departmental digital pathology training programme, validation and deployment. J Clin Pathol. https://doi.org/10.1136/jclinpath-2019-206343

12. Stathonikos N, Nguyen TQ, Spoto CP, Verdaasdonk MAM, van Diest PJ (2019) Being fully digital: perspective of a Dutch academic pathology laboratory. Histopathology 75(5):621-635. https:/doi. org/10.1111/his.13953

13. Retamero JA, Aneiros-Fernandez J, Del Moral RG (2020) Complete digital pathology for routine histopathology diagnosis in a multicenter hospital network. Arch Pathol Lab Med 144(2): 221-228. https://doi.org/10.5858/arpa.2018-0541-OA

14. Browning L, Fryer E, Roskell D, White K, Colling R, Rittscher J, Verrill C (2020) Role of digital pathology in diagnostic histopathology in the response to COVID-19: results from a survey of experience in a UK tertiary referral hospital. J Clin Pathol 74:129-132. https://doi.org/10.1136/jclinpath-2020-206786

15. Hanna MG, Reuter VE, Ardon O, Kim D, Sirintrapun SJ, Schüffler PJ, Busam KJ, Sauter JL, Brogi E, Tan LK, Xu B, Bale T, Agaram NP, Tang LH, Ellenson LH, Philip J, Corsale L, Stamelos E, Friedlander MA, Ntiamoah P, Labasin M, England C, Klimstra DS, Hameed M (2020) Validation of a digital pathology system including remote review during the COVID-19 pandemic. Mod Pathol 33(11):2115-2127. https://doi.org/10.1038/s41379-020-0601-5

16. Evans AJ, Vajpeyi R, Henry M, Chetty R (2020) Establishment of a remote diagnostic histopathology service using whole slide imaging (digital pathology). J Clin Pathol. https://doi.org/10.1136/jclinpath2020-206762

17. He X, Lau EHY, Wu P, Deng X, Wang J, Hao X, Lau YC, Wong JY, Guan Y, Tan X, Mo X, Chen Y, Liao B, Chen W, Hu F, Zhang Q, Zhong M, Wu Y, Zhao L, Zhang F, Cowling BJ, Li F, Leung GM (2020) Temporal dynamics in viral shedding and transmissibility of COVID-19. Nat Med 26(5):672-675. https://doi.org/10. 1038/s41591-020-0869-5

18. Liu Y, Yan LM, Wan L, Xiang TX, Le A, Liu JM, Peiris M, Poon LLM, Zhang W (2020) Viral dynamics in mild and severe cases of COVID-19. Lancet Infect Dis 20(6):656-657. https://doi.org/10. 1016/S1473-3099(20)30232-2

19. Kampf G, Todt D, Pfaender S, Steinmann E (2020) Persistence of coronaviruses on inanimate surfaces and their inactivation with biocidal agents. J Hosp Infect 104(3):246-251. https://doi.org/10. 1016/j.jhin.2020.01.022

20. Guo ZD, Wang ZY, Zhang SF, Li X, Li L, Li C, Cui Y, Fu RB, Dong YZ, Chi XY, Zhang MY, Liu K, Cao C, Liu B, Zhang K, Gao YW, Lu B, Chen W (2020) Aerosol and surface distribution of severe acute respiratory syndrome coronavirus 2 in hospital wards, Wuhan, China, 2020. Emerg Infect Dis 26(7):1583-1591. https:// doi.org/10.3201/eid2607.200885

21. Patel P, Sanghvi S, Malik K, Khachemoune A (2020) Back to the basics: diluted bleach for COVID-19. J Am Acad Dermatol 83(1): 279-280. https://doi.org/10.1016/j.jaad.2020.04.033

22. Williams BJ, Brettle D, Aslam M, Barrett P, Bryson G, Cross S, Snead D, Verrill C, Clarke E, Wright A, Treanor D (2020) Guidance for remote reporting of digital pathology slides during periods of exceptional service pressure: an emergency response from the UK royal college of pathologists. J Pathol Inform 11:12. https://doi.org/10.4103/jpi.jpi_23_20

23. Cross S, Furness P, Igali L, Snead D, Treanor D (2018) Best practice recommendations for implementing digital pathology version 1. The Royal College of Pathologists, London https://www.rcpath. org/uploads/assets/f465d1b3-797b-4297-b7fedc00b4d77e51/Bestpractice-recommendations-for-implementing-digital-pathology.pdf
24. Pantanowitz L, Sinard JH, Henricks WH, Fatheree LA, Carter AB, Contis L, Beckwith BA, Evans AJ, Lal A, Parwani AV, College of American Pathologists Pathology and Laboratory Quality Center (2013) Validating whole slide imaging for diagnostic purposes in pathology: guideline from the College of American Pathologists Pathology and Laboratory Quality Center. Arch Pathol Lab Med 137(12):1710-1722. https://doi.org/10.5858/arpa.2013-0093-CP

25. Fonseca FP, Santos-Silva AR, Lopes MA, Almeida OP, Vargas PA (2015) Transition from glass to digital slide microscopy in the teaching of oral pathology in a Brazilian dental school. Med Oral Patol Oral Cir Bucal 20(1):e17-e22. https://doi.org/10.4317/ medoral.19863

26. Thorstenson S, Molin J, Lundström C (2014) Implementation of large-scale routine diagnostics using whole slide imaging in Sweden: digital pathology experiences 2006-2013. J Pathol Inform 5(1): 14. https://doi.org/10.4103/2153-3539.129452

27. Oeppen RS, Rutherford E, Sadler P, Isaac R, Brennan PA (2020) Virtual ARCP assessment and trainee feedback meetings: facilitating the best experience and practice. Br J Oral Maxillofac Surg. S0266-4356(20)30568-4. doi: https://doi.org/10.1016/j.bjoms. 2020.09.037.

28. Bauer TW, Schoenfield L, Slaw RJ, Yerian L, Sun Z, Henricks WH (2013) Validation of whole slide imaging for primary diagnosis in surgical pathology. Arch Pathol Lab Med 137(4):518-524. https:// doi.org/10.5858/arpa.2011-0678-OA

29. Gupta S, Jawanda MK, Madhushankari GS (2020) Current challenges and the diagnostic pitfalls in the grading of epithelial dysplasia in oral potentially malignant disorders: a review. J Oral Biol Craniofac Res 10(4):788-799. https://doi.org/10.1016/j.jobcr.2020.09.005

30. Gerardo G, Eduardo P, René P (2020) Oral epithelial reactive atypia/ dysplasia: an underestimated true atypia/dysplasia? Med Hypotheses 144:110217. https://doi.org/10.1016/j.mehy.2020.110217

31. Kerawala C, Roques T, Jeannon JP, Bisase B (2016) Oral cavity and lip cancer: United Kingdom National Multidisciplinary Guidelines. J Laryngol Otol 130(S2):S83-S89. https://doi.org/10. 1017/S0022215116000499

32. Wolff KD, Follmann M, Nast A (2012) The diagnosis and treatment of oral cavity cancer. Dtsch Arztebl Int 109(48):829-835. https://doi.org/10.3238/arztebl.2012.0829

33. Mehanna HM, Rattay T, Smith J, McConkey CC (2009) Treatment and follow-up of oral dysplasia - a systematic review and meta-analysis. Head Neck 31(12):1600-1609. https://doi.org/10.1002/hed.21131

34. van der Waal I (2009) Potentially malignant disorders of the oral and oropharyngeal mucosa; terminology, classification and present concepts of management. Oral Oncol 45(4-5):317-323. https://doi. org/10.1016/j.oraloncology.2008.05.016

35. Rodu B, Tate AL, Martinez MG Jr (1987) The implications of inflammation in odontogenic keratocysts. J Oral Pathol 16(10): 518-521. https://doi.org/10.1111/j.1600-0714.1987.tb00684.x

36. Fernandez-Flores A, Saeb-Lima M, Arenas-Guzman R (2014) Morphological findings of deep cutaneous fungal infections. Am J Dermatopathol 36:531-556. https://doi.org/10.1097/DAD. 0b013e31829cc6f3

37. Kent MN, Olsen TG, Feeser TA, Tesno KC, Moad JC, Conroy MP, Kendrick MJ, Stephenson SR, Murchland MR, Khan AU, Peacock EA, Brumfiel A, Bottomley MA (2017) Diagnostic accuracy of virtual pathology vs traditional microscopy in a large dermatopathology study. JAMA Dermatol 153(12):1285-1291. https://doi.org/10.1001/jamadermatol.2017.3284

Publisher's note Springer Nature remains neutral with regard to jurisdictional claims in published maps and institutional affiliations. 